DOI 10.37882/2223-2982.2021.05.39

\title{
РЕЗУЛЬТАТЫ ОБУЧЕНИЯ СТУДЕНТОВ ПО ДИСЦИПЛИНЕ «ПРОФЕССИОНАЛЬНО-СПОРТИВНОЕ СОВЕРШЕНСТВОВАНИЕ. ФЕХТОВАНИЕ» С ПРИМЕНЕНИЕМ ДИСТАНЦИОННЫХ ОБРАЗОВАТЕЛЬНЫХ ТЕХНОЛОГИЙ
}

\section{RESULTS OF STUDENTS TRAINING IN THE DISCIPLINE "PROFESSIONAL AND SPORTS IMPROVEMENT. FENCING" USING DISTANCE EDUCATIONAL TECHNOLOGIES}

\section{O. Shalamova}

P. Bordovskiy

Summary: Nowadays modern society is difficult to imagine without the use of information and communication technologies. The era of informatization has come, which affects almost all spheres of human life, educational activities are no exception. Information technologies in education act as a tool that makes it possible to significantly increase the efficiency of the organization of the educational process, change the forms and methods of pedagogical activity, which in turn allows:

- to conduct the learning process almost continuously;

- to implement educational services remotely;

- to receive education without interrupting the main type of labor activity;

Modern information technologies in education make it possible to quickly adapt to changes in society and in the educational process. A striking example was the events of 2020, when the current unfavorable situation in the country and in the world forced everyone to switch to distance education due to the coronavirus infection pandemic and the subsequent order of the Ministry of Education and Science of Russia [1]. This event made it possible to get an exceptional opportunity - to move on to teaching students, including in sports and pedagogical disciplines using distance educational technologies (DET).

The article discusses the learning outcomes of students of NSU named after P.F. Lesgaft, St. Petersburg with the use of distance educational technologies in the sports and pedagogical discipline "Professional and sports improvement. Fencing".

Keywords: information technology, sports and pedagogical disciplines, student training, professional and sports improvement, distance educational technologies, fencing.
Шаламова Олеся Викторовна

К.п.н., доцент, Национальный государственный университет физической культуры, спорта и здоровья им. П.Ф. Лесгафта Санкт-Петербург shov2006@mail.ru

Бордовский Павел Георгиевич

К.n.н., доцент, Национальный государственный университет физической культуры, спорта и здоровья им. П.Ф. Лесгафта Санкт-Петербург pbord@bk.ru

Аннотация: В настоящее время современное общество сложно представить без использования информационно-коммуникационных технологий. Наступила эпоха информатизации, которая затрагивает практически все сферы жизнедеятельности человека, образовательная деятельность не исключение. Информационные технологии, в образовании выступают как инструмент, который дает возможность существенно повысить эффективность организации учебного процесса, изменения форм и методов педагогической деятельности, что в свою очередь позволяет:

- вести процесс обучения практически непрерывно;

- реализовывать образовательные услуги удаленно;

- получать образование без отрыва от основного вида трудовой деятельности.

Современные информационные технологии в образовании дают возможность оперативно адаптироваться к изменениям, происходящим в обществе и в образовательном процессе. Ярким примером послужили события 2020 года, когда сложившаяся неблагоприятная ситуация в стране и в мире заставила всех перейти на дистанционный формат обучения в связи с пандемией коронавирусной инфекции и последовавшим приказом Минобрнауки России [1]. Это событие позволило получить исключительную возможность - перейти к обучению студентов, в том числе и по спортивно-педагогическим дисциплинам с применением дистанционных образовательных технологий (ДОТ). В статье рассматриваются результаты обучения студентов НГУ им. П.Ф. Лесгафта, Санкт-Петербург с применением дистанционных образовательных технологий по спортивной-педагогической дисциплине «Профессиональноспортивное совершенствование. Фехтование».

Ключевые слова: информационные технологии, спортивно-педагогические дисциплины, обучение студентов, профессионально-спортивное совершенствование, дистанционные образовательные технологии, фехтование.

\section{Введение}

зучение учебных образовательных программ с применением ДОТ в ВУЗах происходит довольно давно, однако это касалось по большей мере общеобразовательных дисциплин, а в преподавании спортивно-педагогических дисциплин применение ДОТ вызывает много вопросов и трудностей. И одна из них самых главных проблем заключалась в формировании 
оценочных средств текущей и промежуточной аттестации в форме практических заданий. И перед нами встал важный вопрос, как оценить результаты обучения по дисциплине, изучение которой направлено на:

- совершенствование своего, индивидуального спортивного мастерства в процессе тренировочных занятий;

- овладение техникой движений, а также техникотактическими действиями в соответствии с особенностями в избранном виде спорта.

На первом этапе нами была разработана модель дистанционного курса, который, как другие нами разработанные программы обучения [2] содержал расписанные требования, которые необходимо соблюдать и выполнять студентам, обучающимся дистанционно, в которые вошли:

- какие и сколько текущих контролей;

- какой вид промежуточной аттестации в конкретном семестре;

- критерии оценивания.

Так же в курсе представлены файлы с:

- технологическими картами;

- содержанием занятий;

- учебно-методическим и информационным обеспечением дисциплины;

- оценочные средства к промежуточной аттестации;

- методическое обеспечение к рабочей программе дисциплины.

В каждом разделе курса студентам открыт доступ к полнотекстовой базе с дополнительной литературой.

Теоретическая и практическая части представлены в виде папки с файлами, которые содержат полную и развернутую информация по изучаемой теме в данном семестре, расположены ссылки на мультимедиа материалы и источники в сети Интернет [3].

На занятиях по установленному расписанию каждый студент индивидуально выполняет практические работы, которые включают в себя все основные действия, представленные в программном материале курса.

Оценочные средства (текущие контроли) размещены в виде файлов с заданиями, требованиями, предъявляемыми и критериев оценки каждому конкретному заданию. Отличительной особенность дисциплины от всех ранее нами разработанных является контролирующая часть. Прохождение текущей аттестации заключалось в выполнении практических заданий. Студенту необходимо выполнить практическое задание по фехтованию, записать видео и отправить преподавателю на проверку.

Применение оценочных средств промежуточной аттестации в форме практических заданий является обязательным условием в данном курсе, так как, освоение программы по дисциплине «Профессионально-спортивное совершенствование (Фехтование)» предполагает дать студентам не только знания, но еще умения и опыт применения полученных навыков в своей трудовой и профессиональной деятельности:

В таблице 1 представлены результаты обучения по окончании 2 -го семестра (экспериментальная группа), где все виды работ, контролей и промежуточной аттестации проходили с помощью дистанционных образовательных технологии и электронного обучения. Промежуточная аттестация проходила посредством видеоконференцсвязи. С обучающимися заранее были обговорены правила и порядок проведения зачёта.

Таблица 1.

Результаты оценивания экспериментальной группы

\begin{tabular}{|c|c|c|c|c|c|c|c|c|c|}
\hline \multirow{2}{*}{ № } & \multirow{2}{*}{ Имя } & TK-1 & TK-2 & TK-3 & TK-4 & TK-5 & TK-6 & \multirow{2}{*}{$\begin{array}{c}\text { Промежуточный } \\
\text { контроль }\end{array}$} & \multirow{2}{*}{ Итого за курс } \\
\hline & & \multicolumn{6}{|c|}{ Задание } & & \\
\hline 1 & Антон & 6 & 7 & 8 & 7 & 6 & 15 & 25 & 74 \\
\hline 2 & Виктория & 6 & 7 & 9 & 7 & 6 & 17 & 26 & 78 \\
\hline 3 & Дина & 7 & 7 & 6 & 6 & 8 & 19 & 26 & 79 \\
\hline 4 & Егор & 7 & 8 & 8 & 7 & 6 & 13 & 27 & 76 \\
\hline 5 & Кристина & 8 & 6 & 8 & 7 & 7 & 14 & 25 & 75 \\
\hline 6 & Майя & 9 & 8 & 9 & 9 & 8 & 17 & 24 & 84 \\
\hline 7 & Максим & 8 & 8 & 7 & 8 & 9 & 16 & 28 & 84 \\
\hline 8 & Маргарита & 9 & 7 & 9 & 8 & 7 & 18 & 28 & 86 \\
\hline 9 & Тимофей & 7 & 6 & 7 & 8 & 6 & 11 & 27 & 72 \\
\hline 10 & Юрий & 7 & 7 & 8 & 7 & 6 & 15 & 25 & 75 \\
\hline
\end{tabular}


Таблица 2.

Результаты оценивания контрольной группы

\begin{tabular}{|c|c|c|c|c|c|c|c|c|c|}
\hline \multirow{2}{*}{ № } & \multirow{2}{*}{ Имя } & TK-1 & TK-2 & TK-3 & TK-4 & TK-5 & TK-6 & \multirow{2}{*}{$\begin{array}{c}\text { Промежуточный } \\
\text { контроль }\end{array}$} & \multirow{2}{*}{ Итого за курс } \\
\hline & & \multicolumn{6}{|c|}{ Задание } & & \\
\hline 1 & Алина & 9 & 8 & 8 & 9 & 8 & 16 & 29 & 87 \\
\hline 2 & Анастасия & 9 & 8 & 7 & 9 & 8 & 20 & 29 & 90 \\
\hline 3 & Евгений & 8 & 8 & 8 & 9 & 7 & 19 & 28 & 87 \\
\hline 4 & Елизавета & 8 & 8 & 9 & 9 & 8 & 18 & 28 & 88 \\
\hline 5 & Кирилл & 8 & 10 & 9 & 8 & 6 & 18 & 28 & 87 \\
\hline 6 & Карина & 10 & 9 & 9 & 10 & 10 & 20 & 30 & 98 \\
\hline 7 & Платон & 9 & 8 & 8 & 9 & 7 & 18 & 26 & 85 \\
\hline 8 & Полина & 8 & 8 & 8 & 9 & 8 & 15 & 28 & 84 \\
\hline 9 & Ульяна & 7 & 6 & 7 & 8 & 8 & 16 & 27 & 79 \\
\hline 10 & Юлия & 8 & 9 & 7 & 9 & 8 & 19 & 26 & 86 \\
\hline
\end{tabular}

Далее нами был проведен сравнительный анализ полученных данных с результатами образовательной деятельности студентов, которые ранее проходили освоение программы в классической форме (таблица 2), посещая занятия спортивном зале, сдавая текущие контроли и промежуточную аттестацию при личном присутствии.

Статистическая проверка результатов исследования с применением непараметрического рангового критерия Манна-Уитни (Вилкоксона) для независимых выборок (Mann-Whitney (Wilcoxon) W test), группы несвязанные, соответствие нормальному распределению не проверялось, альтернатива двухсторонняя показала, что отличия контрольной и экспериментальной группы являются существенными.

Это говорит о том, что обучение с помощью дистанционных образовательных технологий по дисциплинам, которые направлены на совершенствование спортивного и технико-тактического мастерства, являются менее эффективными чем при классическом варианте проведения занятий. Оно уступает по результативности классической форме и может выступать только, как вспомо- гательный элемент.

\section{Выводы}

1. Применение дистанционных образовательных технологий в образовательном процессе студентов, кафедры теории методики фехтования по спортивно-педагогической дисциплине «Профессионально-спортивное совершенствование (Фехтование)» показало более низкую результативность, чем классическая форма проведения занятий.

2. Фехтование, это вид единоборства, где процесс обучения - целая система овладения двигательными навыками и огромным комплексом специальных качеств и умений. А фехтовальный бой, это спортивный поединок, и без полноценного тренировочного процесса повысить техническую и тактическую подготовленность, освоить должные тренировочные нагрузки не представляется возможным. Однако, изучение теоретических разделов дисциплины и методических рекомендаций могут проводиться с применением ДОТ практически без потери качества.

\section{ЛИТЕРАТУРА}

1. Приказ Минобрнауки России от 11.11 .2020 N 1402 «0 мерах по снижению рисков распространения новой коронавирусной инфекции в образовательных организациях высшего образования» // Консультант Плюс. Режим доступа: http://www.consultant.ru/law/hotdocs/65692.html/.

2. Бордовский П.Г., Шаламова О.В. Проверка адекватности модели дистанционного курса дисциплины «технологии спортивной тренировки в избранном виде спорта (фехтование)» требованиям ФГОС // Труды кафедры биомеханики университета имени П.Ф. Лесгафта 2019г. Выпуск 13 Ежегодный сборник научных трудов. Санкт-Петербург: Нац. гос. ун-т физ. культуры, спорта и здоровья им. П.Ф. Лесгафта, 2019. С. 22-27.

3. Официальный сайт НГУ им. П.Ф. Лесгафта. Санкт-Петербург. Обучение. Образовательные программы. Режим доступа: http://www.lesgaft.spb.ru/ru/rpd/ sport. 